\title{
A Comissão Especial de Investigação Sumária da UFRGS (1964)*
}

\author{
The Special Commission for Summary Investigation \\ of UFRGS (1964)
}

Jaime Valim Mansan**

Resumo: A atuação da Comissão Especial de Investigação Sumária, instalada na Universidade Federal do Rio Grande do Sul (UFRGS) em maio de 1964, resultou no expurgo de doze professores daquela instituição. Foi uma das várias ações da chamada "Operação Limpeza", um amplo processo coercitivo realizado em todo o Brasil nos primeiros meses após o golpe de 1964.

Palavras-chave: Expurgo. Educação superior. Ditadura Civil-Militar

Abstract: The action of the Special Commission for Summary Investigation, created at UFRGS in may 1964, has resulted in the purge of twelve teachers from that institution. It was one of many actions caused by the so called "Operação Limpeza", a large coercive process promoted in Brazil during the first months after the 1964's coup d'état.

Keywords: Purge. Higher education. Civil-Military Dictatorship

* Este artigo é uma versão revisada e atualizada do cap. 2 de Os expurgos na UFRGS: afastamentos sumários de professores no contexto da Ditadura Civil-Militar (1964 e 1969), dissertação defendida junto ao Programa de Pós-Graduação em História da Pontifícia Universidade Católica do Rio Grande do Sul - PUCRS, com apoio da Coordenação de Aperfeiçoamento de Pessoal de Nível Superior. Dentre as fontes utilizadas, destacam-se as atas da Comissão Especial de Investigação Sumária da Universidade Federal do Rio Grande do Sul - UFRGS, integrantes do Fundo Laudelino Teixeira Medeiros, disponível no Centro de Documentação da Universidade de Caxias do Sul.

** Doutorando em História na PUCRS, com apoio do Conselho Nacional de Desenvolvimento Científico e Tecnológico e orientação do Prof. Dr. Helder Gordim da Silveira. Licenciado em História pela UFRGS (2006). Correio eletrônico: jaimemansan@gmail.com 
Logo após a deposição de Goulart, em abril de 1964, alguns setores da sociedade brasileira sofreram intensa repressão, sobretudo aqueles mais ligados ao governo deposto e a partidos e movimentos de esquerda. Feito isso, teve início um amplo processo de "investigação sumária", chamado de "Operação Limpeza" pelos militares e civis que o promoveram. Sua meta era afastar possíveis opositores da estrutura estatal e das principais instituições da sociedade civil. A vasta investigação, que durou meses e teve abrangência nacional, orientou a realização de grandes ações repressivas, ao mesmo tempo em que foi utilizada na busca de legitimação daquele processo repressivo. O campo da educação superior, uma das áreas mais visadas pelo grupo no poder, foi significativamente atingido na ocasião.

A criação da Comissão Especial de Investigação Sumária da Universidade Federal do Rio Grande do Sul (CEIS) foi apenas uma das medidas levadas a cabo no estado em função da "Operação Limpeza". Seguindo o padrão nacional, um amplo processo de controle coercitivo foi posto em prática no Rio Grande do Sul: 92 intervenções foram decretadas nos primeiros dias após o golpe, 61 delas na capital. Muitas em entidades de representação estudantil, inspetorias de ensino e outros órgãos ligados à educação. Seis meses depois, a maioria dessas ações de controle já havia sido encerrada, "por nomeação de titulares e conclusão de inquéritos", restando seis entidades sob intervenção na capital e onze no interior do estado (Intervenção, 1964).

A intervenção militar concentrou-se nas instituições onde o grupo no poder acreditava estar presente a "subversão". Alguns militares foram designados para as principais entidades estudantis vinculadas à UFRGS. Paralelamente, dirigentes universitários eram instados a colaborar com ações da "Operação Limpeza". Na UFRGS, é significativo disso a Circular no 31 de 14 de abril de 1964, do reitor José Carlos Fonseca Milano ao Diretor do Instituto de Filosofia, transmitindo solicitação do Secretário de Segurança do Estado no sentido do fornecimento das "relações de alunos de todas as faculdades, escolas e institutos subordinados a essa reitoria", em caráter de urgência, "tendo em vista a necessidade do serviço de segurança" (UFRGS, 1964k).

De 1952 a 1964, foi reitor da UFRGS o prof. Elyseu Paglioli. Considerado um dos pioneiros da neurocirurgia no Brasil, tinha forte vínculo com o trabalhismo. Amigo pessoal de Vargas, chegou a ser prefeito de Porto Alegre entre $1^{\circ}$ de fevereiro e 17 de novembro de 1951, por indicação de Ernesto Dornelles (primo de Vargas e, na ocasião, governador do Rio Grande do Sul). Em 1952, assumiu a Reitoria da 
UFRGS, permanecendo na função até o golpe de $1964 .{ }^{1}$ Não se sabe se foi destituído pelo novo governo ou se saiu por iniciativa própria. De todo modo, parece provável ter havido alguma relação entre o súbito fim de seu longo e bem sucedido reitorado e as drásticas mudanças políticas vividas pelo país em 1964.

Diante da saída de Paglioli, o vice-reitor Pery Pinto Diniz da Silva optou pela renúncia (UFRGS, 1964j). Assim, Luis Leseigneur de Faria assumiu interinamente a Reitoria. No curto período em que permaneceu na função, Leseigneur de Faria emitiu a Circular $n^{0} 35$, dirigida aos diretores das unidades de ensino e pesquisa, que deveriam divulgá-la entre docentes, discentes e servidores técnico-administrativos. Manifestava o apoio da reitoria aos "patrióticos objetivos" do "movimento democrático restaurador" que depusera Goulart, e solicitava que todos se abstivessem de qualquer ação que pudesse "importar em perturbação da ordem, dos bons costumes e no desrespeito às autoridades em geral" (UFRGS, $\mathrm{s} / \mathrm{d}$ ).

José Carlos Fonseca Milano, confirmado por Castello Branco a partir de lista tríplice a ele enviada pelo Conselho Universitário (CONSUN), assumiu como reitor em 18 de maio de 1964, permanecendo na função até 1968. A lista havia sido votada em 25 de abril de 1964, no CONSUN, em reunião convocada por Leseigneur de Faria (UFRGS, 1964j). Além de Fonseca Milano, foram indicados, em ordem de preferência, o próprio Leseigneur de Faria e Luiz Pilla.

\section{A criação da Comissão}

Em 1964, segundo Angélica de Moraes, o governo ditatorial teria assumido "integralmente a intervenção e o expurgo" nas universidades, com a única exceção da UFRGS, onde as Forças Armadas teriam conseguido "dividir responsabilidades" naquela "incômoda tarefa" (Moraes, 1979). Houve, entretanto, outras situações em que professores atuaram nas investigações sumárias promovidas pela "Operação Limpeza". Na Universidade de São Paulo, por exemplo, o reitor Gama e Silva nomeou três professores de sua confiança para a formação da comissão especial de investigação sumária daquela instituição (ADUSP, 2004).

A constatação de que, em outras universidades, professores também atuaram na repressão a docentes, discentes e servidores técnicoadministrativos não deve conduzir à suposição de que todos os processos repressivos promovidos nas universidades em 1964 tenham sido idênticos.

\footnotetext{
1 Entre 19/09/1962 e 24/02/1963, afastou-se para assumir o Ministério da Saúde.
} 
No caso da UFRGS, por exemplo, houve significativas singularidades, o que talvez tenha levado Moraes a postular a observação citada. De fato, a constituição de um grupo composto por um representante de cada unidade de ensino parece ter sido especificidade da UFRGS. Segundo a ata da reunião de instalação da comissão, essa formação teria sido uma opção de Fonseca Milano, acatando sugestão da Faculdade de Direito de Porto Alegre (UFRGS, 1964a).

Tal entendimento é ainda mais provável se observadas as instruções passadas pelo ministro da Educação e Cultura Flávio Suplicy de Lacerda às reitorias do país, para a execução da investigação sumária nas instituições de educação superior. Em 20 de abril de 1964, o MEC entrara em contato com a Reitoria da UFRGS por telegrama, informando o teor da Portaria $n^{\circ} 259$, daquela data, que determinava a instauração de inquéritos nas universidades brasileiras. Por meio da referida portaria, segundo o telegrama, o ministro, "usando [de] suas atribuições e considerando [os] termos [do] Ato Institucional [ $\left.\mathrm{n}^{\mathrm{o}} 1\right]^{1}$ ", determinou que, "para dar cumprimento [ao] Ato Institucional, nas universidades [os] inquéritos serão mandados instaurar, nas instituições [de] ensino isoladas, pelos seus diretores". Além disso, definia também que "[os] relatórios serão remetidos com pareceres conclusivos ao Ministro [de] Estado, dentro [do] prazo [de] 30 dias a contar [de] 20 [de] abril [do] corrente, sem prorrogação" (UFRGS, 1964a). ${ }^{2}$

Dessa correspondência é possível perceber três aspectos importantes:

1. A referência ao AI-1 como tentativa de legitimar a aplicação da medida repressiva;

2. A busca de centralização da condução dos processos de controle no presidente e em seus ministros;

3. A orientação geral dada pelo ministro às instituições de educação superior para a realização dos inquéritos, que deveriam ser instaurados em cada unidade de ensino por seus diretores.

Apesar da portaria do MEC ser clara quanto aos prazos, assinalando que todo o trabalho deveria estar concluído antes de 20 de maio de 1964, o início do processo na UFRGS, marcado pela instalação da CEIS naquela universidade, só ocorreu de fato em 18 de maio daquele ano, quando Fonseca Milano foi confirmado como reitor pelo MEC. Aparentemente, a troca de reitores foi o motivo do atraso.

2 Nas citações diretas, optou-se por corrigir eventuais erros ortográficos encontrados nas fontes. 
Entre o envio da mensagem ministerial e a instalação da CEIS, outro telegrama do MEC foi recebido pela Reitoria da UFRGS. Nele, Suplicy de Lacerda determinava que o reitor, "em aditamento [ao] aviso [ $\left.\mathrm{n}^{\circ}\right]$ 705 de 22 [do] corrente", entrasse em "entendimento [com o] Comando [do] III Exército, solicitando-lhe [a] indicação [de] um servidor militar", com o objetivo de "acompanhar [os] processos sumários [referentes ao] Artigo $7^{\circ}$ [do] Ato Institucional [n] essa universidade, assessorando [a] comissão designada [por] Vossa Magnificência nos termos [da] nossa Portaria [n ${ }^{\circ} 259$ de 20 [de] abril" (UFRGS, 1964a).

Observa-se, em primeiro lugar, a referência à Portaria $n^{0} 259$, que incumbia o reitor de designar a comissão. O fato de o ministro incumbir os reitores de tal tarefa explica a diferença na composição das comissões de cada universidade. Na USP, Gama e Silva optou por formar a comissão com três docentes de sua confiança. Na UFRGS, Fonseca Milano decidiu aceitar a sugestão da Faculdade de Direito e delegar a cada congregação a tarefa de nomear seus representantes. Qual terá sido o motivo dessa escolha de Fonseca Milano? Dividir responsabilidades em um processo repressivo movido contra os próprios colegas? Torná-lo mais representativo? Aumentar a eficácia da investigação?

Outro ponto importante mencionado no telegrama é a orientação para "entendimento [com o] Comando [do] III Exército", a fim de que este indicasse à Reitoria um militar para "acompanhar [os] processos sumários". O oficial indicado pelo III Exército foi o gen. Jorge Cesar Garrastazu Teixeira, que se fez presente em todas as reuniões desde a instalação da CEIS, atuando efetivamente como o coordenador de seus trabalhos, a despeito de ser sistematicamente referido nas atas como "assessor militar". Talvez para evitar sua exposição, ou mesmo por receio de represálias, costumava andar à paisana na universidade (Souza, 2007).

\section{A escolha dos componentes}

A CEIS foi instalada na tarde de 18 de maio de 1964, pela Portaria $\mathrm{n}^{\circ} 885$, decretada naquela data por Fonseca Milano. Fazia referência à Portaria $\mathrm{n}^{\mathrm{o}} 259$, de 20 de abril de 1964, decretada por Suplicy de Lacerda, bem como ao artigo $7^{\circ}$ do Ato Institucional e ao Decreto $\mathrm{n}^{\circ}$ 53.897, de 27 de abril de 1964, sendo este a regulamentação do referido artigo do AI-1 (UFRGS, 1964a).

No Art. $1^{\circ}$ da Portaria $n^{\circ} 885$, eram definidos os objetivos da CEIS e, almejando legitimidade para a comissão ou simplesmente seguindo 
o protocolo, fazia-se referência ao AI-1 e ao Decreto $\mathrm{n}^{\circ} 53.897 .{ }^{3}$ Vale lembrar que o Art. $7^{\circ}$ do AI-1 lançara formalmente as diretrizes para o trabalho de "investigação sumária" vinculado à "Operação Limpeza", e que o parágrafo $1^{\circ}$ do Art. $3^{\circ}$ do Decreto $n^{\circ} 53.897$ assinalava a responsabilidade dos ministros como promotores das investigações no âmbito de seus respectivos ministérios. ${ }^{4}$

O Art. $2^{\circ}$ da Portaria $n^{\circ} 885$ designava os componentes da CEIS, indicados pelas congregações. Os quatorze docentes designados para a comissão eram: Luiz Carlos Guimarães (Faculdade de Odontologia de Porto Alegre), Moysés Westphalen (Faculdade de Agronomia e Veterinária), Jacy Carneiro Monteiro (Faculdade de Medicina), Saviniano de Castro Marques (Escola de Engenharia), Ney Messias (Faculdade de Direito de Porto Alegre), Amadeu Fagundes da Rocha Freitas (instrutor de Ensino da Escola de Engenharia, representante da Faculdade de Arquitetura), Paulo Maurell Moreira (Faculdade de Farmácia), Nagipe Buaes (Faculdade de Ciências Econômicas), Gastão Coelho Pureza Duarte (Faculdade de Odontologia de Pelotas), Delfim Mendes da Silveira (Faculdade de Direito de Pelotas), Lourenço Mario Prunes (Faculdade de Filosofia), Zacarias Valiati (Escola de Artes), Neya Machado da Silva (Escola de Enfermagem) e Othon Sá Castanho (Escola de Geologia). ${ }^{5}$

Além deles, fez parte da comissão, como mencionado, o gen. Teixeira. No entanto, a portaria não fazia qualquer menção à participação de um "assessor militar", nem de outra instituição (civil ou militar) ou indivíduo não pertencente à UFRGS.

Na ocasião, a congregação da Faculdade de Arquitetura negou-se a indicar um representante para a CEIS. ${ }^{6}$ Por esse motivo, Freitas foi nomeado representante da Faculdade de Arquitetura. Com o impasse, ele teria se apresentado voluntariamente ao diretor daquela unidade,

3 “Art. $1^{\circ}$ É instituída, na Universidade do Rio Grande do Sul, a Comissão Especial destinada a proceder à investigação sumária de que trata o $\S 1^{\circ}$ do art. $7^{\circ}$ do Ato Institucional e o $\S$ $1^{\circ}$ do art. $3^{\circ}$ do Decreto ${ }^{\circ} 53.897^{\prime \prime}$ (UFRGS, 1964a).

4 Ver Mansan (2009, p. 69-76).

5 Na época, as Faculdades de Direito e de Odontologia de Pelotas eram vinculadas à UFRGS. Em 1969, a fusão delas com as unidades de ensino e pesquisa vinculadas à Universidade Federal Rural do Rio Grande do Sul, como a Faculdade de Agronomia Eliseu Maciel e a Faculdade de Ciências Domésticas, deu origem à Fundação Universidade Federal de Pelotas (UFPel).

6 Sobre isso, afirmou Demétrio Ribeiro em meados da década de 1990: "Não posso omitir aqui que a categoria profissional dos arquitetos honrou-se com a impossibilidade de se achar um colega para integrar a chamada Comissão de inquérito, na realidade um comitê de falsas delações" (Ribeiro, 1994, p. 15). 
prof. João Baptista Pianca, para representá-la na CEIS (ADUFRGS, 1979, p. 25). ${ }^{7}$ Segundo Dreifuss, Freitas era um dos líderes regionais do IPES (Instituto de Pesquisas e Estudos Sociais) no Rio Grande do Sul (Dreifuss, 2006, p. 199). ${ }^{8}$ Tal vínculo com o grupo no poder e seu alinhamento ideológico com o novo regime podem ter sido algumas das principais razões de seu interesse em participar da comissão.

Ainda em relação à Portaria $n^{\circ} 885$, cabe apontar que, em seu Art. $3^{\circ}$, determinava que, após a conclusão das investigações, o relatório resultante deveria ser encaminhado ao ministro da Educação e Cultura. No último artigo, reforçava a referência ao Art. $7^{\circ}$ do AI-1 e ao Decreto n 53.897 (UFRGS, 1964a).

Por sugestão de Fonseca Milano, a comissão elegeu um presidente. Prunes, representante da Faculdade de Filosofia e juiz de direito, foi escolhido por aclamação, a partir de uma sugestão de Buaes (UFRGS, 1964a).

\section{Subcomissões}

Assim como o relativamente amplo número de membros da comissão principal, as subcomissões também constituíram uma especificidade da CEIS. A ideia surgiu já na reunião de instalação. Contrário a Prunes, que propunha a criação de uma única subcomissão de três membros para os trabalhos de investigação, Messias sustentou a manutenção da comissão principal, assessorada por um grupo de subcomissões, ideia que prevaleceu (UFRGS, 1964a).

Algumas subcomissões passaram a se reunir nas dependências da Reitoria, outras nas faculdades das quais seus membros eram oriundos. A comissão principal utilizava a Sala do CONSUN, amplo e solene espaço localizado no prédio da Reitoria (Moraes, 1979).

Além de servir de elo entre a CEIS, o III Exército e o DOPS/RS, o gen. Teixeira atuou significativamente na supervisão das subcomissões, disso sendo sintomático o fato de ter viajado a Pelotas, em 11 de junho de 1964, com o objetivo de conhecer o andamento dos trabalhos da subcomissão "B” (UFRGS, 1964e).

7 Pianca foi diretor da Faculdade de Arquitetura de 17/05/1962 a 17/05/1965. Foi reitor interino quando, de 27/09/1962 a 01/03/1963, Paglioli assumiu o Ministério da Saúde (UFRGS, 1962; 1963).

8 Sobre o Instituto de Pesquisas Econômicas e Sociais do Rio Grande do Sul (IPESUL), ver Moraes (2012). 
Por sugestão de Marques, foi criada uma subcomissão para a elaboração de um regimento para a CEIS, composta por ele, pelo gen. Teixeira e por Messias. A criação de um regimento interno para uma comissão cujas atividades durariam apenas alguns meses aponta para a preocupação daquele grupo com os aspectos formais de sua atuação. Hábitos arraigados? Estratégia de defesa em uma conjuntura onde reinava a incerteza? Ambos os motivos parecem plausíveis, inclusive concomitantemente, um reforçando o outro.

$\mathrm{Na} 1^{\mathrm{a}}$ reunião ordinária da CEIS, em 21 de maio de 1964, foi aprovado com alterações o projeto de regimento da comissão. Com dezenove itens, o regimento determinava, dentre outros pontos, que cada subcomissão teria ampla autonomia para tratar de "atentados contra a segurança do país, o regime democrático e a probidade da administração pública" na universidade. Permitia também que as subcomissões obtivessem informações diretamente com órgãos da "comunidade de segurança e informações". Estabelecia que ao "indiciado" caberia escolher entre apresentar sua defesa textual ou oralmente, e que o "assessor militar" tinha "amplos poderes" para atuar tanto na comissão principal quanto em qualquer subcomissão.

Na ocasião, também foram definidas as subcomissões: "A" (Escolas de Engenharia e de Geologia e Faculdades de Arquitetura e de Agronomia e Veterinária, todas de Porto Alegre); "B" (Faculdades de Direito e de Odontologia, ambas de Pelotas); "C" (Faculdades de Enfermagem, de Farmácia, de Medicina e de Odontologia, todas de Porto Alegre); e "D" (Escola de Artes e Faculdades de Direito, de Ciências Econômicas e de Filosofia, todas de Porto Alegre) (UFRGS, 1964b).

A subcomissão destinada a investigar a reitoria e os institutos autônomos, no entendimento dos membros da CEIS, deveria ter uma formação específica. Através de ofício, a comissão solicitou a Fonseca Milano a indicação de dois membros para composição daquela subcomissão. Após designar alguns servidores técnico-administrativos que encontraram motivos justificáveis, na visão do reitor, para recusar a incumbência, Fonseca Milano enviou à CEIS o Ofício n ${ }^{\circ} 2156$, de 9 de junho de 1964, por meio do qual sugeria que a comissão escolhesse dois de seus membros para a formação da subcomissão.

A maioria dos membros da CEIS entendia que aquela subcomissão deveria ser composta por funcionários da reitoria. Essa opinião teria sido levada ao reitor. Sabe-se que tal subcomissão chegou a ser criada e, ainda que se desconheça parcialmente sua composição, um de seus membros, que a representava na comissão principal e que havia sido 
indicado por Fonseca Milano, era o prof. David Mesquita da Cunha, diretor do Instituto de Física na época (UFRGS, 1964f; 1964g).

\section{Substituições}

Por iniciativa própria, três membros da CEIS foram substituídos logo nas primeiras reuniões. Um deles foi o próprio presidente da comissão.

Prunes era juiz do Tribunal de Justiça do Rio Grande do Sul. Já na $1^{a}$ reunião, manifestou entender que não poderia seguir na comissão, em função do item I do Art. no 96 da Constituição Federal de 1946, que vedava ao juiz "exercer, ainda que em disponibilidade, qualquer outra função pública, salvo o magistério secundário e superior e os casos previstos nesta Constituição, sob pena de perda do cargo judiciário". Disse que, em função daquele impedimento, até recusara "convites de professores de sua faculdade para fazer parte de listas tríplices relativas à escolha de diretor da Faculdade de Filosofia", por entender "que o preceito constitucional só permite ao juiz o exercício do cargo de professor" (UFRGS, 1964b). Comentou ainda que chegara a procurar, para esclarecer a questão, o Conselho Superior da Magistratura que, no entanto, não quisera se manifestar oficialmente, por entender que a apreciação deveria ser do Tribunal Pleno. Entretanto, segundo Prunes, "oficiosamente os membros daquele Conselho pronunciaramse contrariamente à participação do orador na Comissão Especial, face ao dispositivo constitucional antes mencionado" (UFRGS, 1964b). Por isso, Prunes sugeria que outro membro da CEIS assumisse interinamente o cargo até que fosse eleito um novo presidente.

Messias observou que a atuação na CEIS seria "um prolongamento, praticamente, de suas funções de professor" e sugeriu que continuasse como presidente da comissão. Fazia, inclusive, "uma particular censura, do ponto de vista técnico", às alegações de Prunes, tendo sido sua posição apoiada pelos demais. Prunes aceitou permanecer na função, mas observou que pediria um pronunciamento do Tribunal Pleno, ficando sua decisão em aberto (UFRGS, 1964b).

Chama a atenção que, em três dias, a opinião de Prunes tenha mudado tanto. Não deveria ter ciência daquele impedimento constitucional quando a CEIS foi instalada? Por que não se manifestou na ocasião? Ainda que possa ter ocorrido um simples lapso, parece mais provável que, diante da conjuntura instável, estivesse sendo cuidadoso. Indicado pela congregação da Faculdade de Filosofia para representá-la na comissão, 
talvez tenha optado por não contrariar a decisão, o que bem poderia render-lhe problemas futuros. Também pode ter imaginado que a criação da CEIS teria ocorrido no sentido de simular, para o governo ditatorial, uma atitude de obediência, de modo a evitar confrontos perigosos, e não para efetivamente perseguir professores, alunos e servidores técnico-administrativos. A suposição de que a criação da CEIS seria apenas uma forma de não entrar em atrito com o governo ditatorial é confirmada por pessoas que vivenciaram a UFRGS daqueles primeiros meses após o golpe. ${ }^{9}$

$\mathrm{Na}$ reunião seguinte, Prunes afirmou que o Tribunal Pleno havia declarado sua participação na CEIS incompatível com o cargo de juiz. Comentou que já havia comunicado a situação ao reitor e a ele solicitado sua substituição na comissão. Por fim, manifestou seu desejo de que o grupo soubesse "cumprir serenamente sua missão", para que a universidade pudesse "se reintegrar em seus destinos" (UFRGS, 1964c).

Cauteloso, afastou-se da comissão com base em um motivo que não podia ser contestado, por se tratar de determinação do Tribunal de Justiça e por ter a anuência do reitor. Sua última afirmação foi emblemática de sua atuação na comissão. Podia ser interpretada como um desejo de que se conseguisse afastar a "subversão" da UFRGS sem maiores transtornos, permitindo que se voltasse à normalidade das atividades acadêmicas prejudicadas pela atuação de "subversivos". Também podia ser vista como manifestação de expectativa de que a CEIS cumprisse formalmente as obrigações a ela impostas pelo governo ditatorial sem, no entanto, realizar de fato uma caça às bruxas na universidade, possibilitando o pleno retorno da instituição à sua real função de espaço de ensino e produção de conhecimento.

Apesar de Messias seguir manifestando-se contra a saída de Prunes, tratava-se de fato consumado. Diante disso, Buaes foi eleito presidente por aclamação (UFRGS, 1964c).

Ainda na $2^{\mathrm{a}}$ reunião, outra substituição foi feita. Por telegrama, Pureza Duarte, representante da Faculdade de Odontologia de Pelotas e presidente da subcomissão "B", informava a posse da prof $f^{a}$ Rosa Russomano de Souza Lima, que substituíra Mendes Silveira por decisão da congregação de Direito de Pelotas (UFRGS, 1964c).

Tendo Buaes questionado a validade de tal substituição, Messias afirmou que "era perfeitamente regular, pois a congregação pode

9 Cláudio Accurso, professor "indiciado" pela CEIS e expurgado em 1964, é um exemplo: "Eu tinha a impressão (...) de que a comissão iria fazer o jogo de dizer para os militares 'Olha, nós concordamos em limpar a Universidade', mas supunha que tais episódios não teriam consequências. Mas ocorreu o contrário” (Accurso, 2006). 
regressar sobre ato que praticara" (UFRGS, 1964c). Messias era um dos mais ativos participantes da comissão e, como o gen. Teixeira, um dos mais respeitados.

Ainda um terceiro docente deixaria a comissão. Westphalen participara da reunião de instalação e das duas primeiras reuniões ordinárias. No entanto, na terceira, em 4 de junho de 1964, ausentou-se. Buaes, já como presidente, leu o "pedido de demissão" de Westphalen, justificado "por motivos particulares". Em vista disso, a comissão solicitou à Faculdade de Agronomia e Veterinária outro representante (UFRGS, 1964d).

$\mathrm{Na} 4^{\mathrm{a}}$ reunião, em 8 de junho, Buaes informou que o prof. Cícero Menezes de Moraes havia sido escolhido pela faculdade como substituto de Westphalen (UFRGS, 1964e). Na $5^{\text {a }}$ reunião, realizada no dia seguinte, o caso de Westphalen foi amplamente debatido. Os diretores das faculdades correspondentes à subcomissão "A" estavam presentes, incluindo Mozart Pereira Soares, diretor da Faculdade de Agronomia e Veterinária.

De início, Guy Hellen Sosa Britto, secretário da CEIS, leu o relatório anteriormente enviado pela Faculdade de Agronomia e Veterinária à comissão. Feito isso, Soares observou que aquele documento, apresentado por Westphalen (que o substituíra na direção daquela unidade de ensino em sua ausência), estava correto, e que não tinha qualquer elemento que pudesse trazer ao plenário "no tocante a malversação de dinheiros públicos, atos de corrupção ou atividades subversivas atentatórias ao regime democrático, tanto de professores como de funcionários ou estudantes" (UFRGS, 1964f).

A seguir, foi lido um ofício enviado por Westphalen, no qual apresentava explicações para seu afastamento da CEIS. É significativo que Teixeira tenha a seguir solicitado "que fosse lida (...) a ficha de informações sobre o prof. Westphalen (...) enviada pelo III Exército”. Moraes declarou que um item da ficha não correspondia à realidade, pois ele próprio havia votado a favor de Westphalen e nada havia a seu respeito "com relação ao comunismo" (UFRGS, 1964f). Em Universidade e Repressão, há menção a quatro acusações que o III Exército teria dirigido a Westphalen e que, provavelmente, correspondem à referida ficha:

$1^{\mathrm{a}}$ ) em certa ocasião, teria 'falado mal' do III Exército; $2^{\mathrm{a}}$ ) seria 'amigo de comunistas'; $3^{\mathrm{a}}$ ) teria sido eleito, para a CEIS, por 'quatro comunistas' da Faculdade de Agronomia e Veterinária; e 4ª) seria 'protetor' do prof. Luiz Carlos Pinheiro Machado, também dessa faculdade (ADUFRGS, 1979, p. 28). 
Percebe-se que Moraes não se opôs frontalmente às afirmações feitas pelo Exército, mas buscou marcar discordância em relação à afirmação de que Westphalen teria sido eleito por "quatro comunistas" daquela faculdade, já que um desses quatro professores era ele.

Soares ainda encaminhou à CEIS um relatório com vários documentos, dentre eles a ata da reunião da congregação da Faculdade de Agronomia e Veterinária na qual Westphalen fora eleito seu representante na CEIS. O diretor afirmava ter ocorrido "não somente distorção, mas até uma completa inversão no sentido das palavras então pronunciadas" por ele e por Westphalen, considerando aquilo algo intolerável. Fazia uma forte defesa de Westphalen, afirmando que transmitia aquelas informações "em defesa não só de um dos mais ilustres professores" daquela faculdade, "reconhecido como um modelo de dignidade em sua vida pública e privada", mas também "em nome da verdade" (UFRGS, 1964g).

A corajosa intervenção de Soares ajudou a livrar Westphalen das ações repressivas que já pareciam inevitáveis. No entanto, por indicação da CEIS e talvez como uma forma de punir Westphalen indiretamente, o prof. Luiz Carlos Pinheiro Machado, aquele que a "comunidade de segurança e informações" considerava um 'protegido' de Westphalen, acabou sendo expurgado da universidade (UFRGS, 1964g).

\section{Depoimentos}

$\mathrm{Na} 5^{\mathrm{a}}$ reunião da CEIS, todos os diretores das faculdades da subcomissão "A" estavam presentes, para prestar esclarecimentos à CEIS sobre a "subversão" em suas respectivas unidades de ensino e pesquisa. Eram eles: Luis Leseigneur de Faria (Escola de Engenharia), João Baptista Pianca (Faculdade de Arquitetura), Milton Luiz Laquintinie Formoso ("Diretor em exercício" da Escola de Geologia) e, como mencionado, Mozart Pereira Soares (Faculdade de Agronomia e Veterinária).

A eles Buaes informou os dois "quesitos a serem respondidos", que haviam sido definidos pelo gen. Teixeira na reunião anterior (UFRGS, 1964e).

O primeiro questionava-os sobre "irregularidades nas Faculdades (...), notadamente de casos de corrupção e malversação dos dinheiros públicos, para fins subversivos, uma vez que este particular não foi abordado no ofício sigiloso" (UFRGS, 1964f). O segundo item indagava se, "como membro do Conselho Universitário, ou por outras fontes", poderiam "apontar indícios ou informações de fatos na universidade" 
que deveriam ser estudados pela comissão por dizerem respeito a "subversão, comunismo ou corrupção" (UFRGS, 1964f). Neste último caso, não se tratava de ouvir os diretores apenas sobre os "problemas" em suas respectivas unidades de ensino e pesquisa, mas também de recolher deles "indícios ou informações" relativos à universidade em geral. A menção ao CONSUN é significativa, pois todos os diretores faziam parte do órgão máximo deliberativo da instituição e, portanto, poderiam estar a par dos principais acontecimentos da vida universitária no período imediatamente anterior ao golpe.

Para cada unidade de ensino, o secretário da CEIS lia o relatório previamente enviado, depois se ouvia o pronunciamento dos respectivos diretores e, por fim, os membros da CEIS apresentavam outras perguntas a eles. Em uma delas, Laudelino Medeiros, presidente da Subcomissão "D" e representante da Faculdade de Filosofia (substituíra Prunes), questionava os diretores sobre a existência de algum "estudante profissional", aquele "que repete intencionalmente, ou, então, que permanece na escola, através de outros cursos, com a intenção de ficar no ambiente universitário", "com finalidades estranhas e contrárias aos objetivos da universidade e, algumas vezes, com fins subversivos". Travou-se amplo debate acerca da existência de "estudantes profissionais" nas escolas ali representadas. Após os 'depoentes' deixarem a reunião, Messias sugeriu que as reuniões com os outros diretores fossem suspensas. Claramente, alguns membros da CEIS não estavam satisfeitos com a participação dos "convidados". Monteiro, apoiando a sugestão de Messias, observou ainda que os diretores "procuram defender as suas escolas, quando os integrantes das subcomissões sabem que existem elementos fortemente implicados, e esses elementos não são relatados por alguns dos srs. diretores" (UFRGS, 1964f).

Além dos diretores, a comissão também solicitou o depoimento de estudantes, servidores técnico-administrativos, professores e até mesmo do ex-reitor Elyseu Paglioli. À exceção dele, dos diretores e de alguns professores, que se apresentaram à comissão principal, os demais prestavam depoimento às subcomissões, que realizavam uma triagem das informações. A subcomissão "D”, por exemplo, convocou a depor, dentre outros, o secretário da Faculdade de Direito e alguns presidentes de centros acadêmicos (UFRGS, 1964g).

A $7^{\mathrm{a}}$ reunião foi marcada pela presença de Paglioli e por debates em torno de sua administração. Sua convocação surgira em função de uma polêmica envolvendo a cessão do Salão de Atos. Na ocasião, Medeiros havia questionado Pery Pinto Diniz da Silva sobre a cessão do Salão 
de Atos para uma atividade do Movimento Nacionalista Feminino, a partir de uma solicitação de Neusa Brizola, quando Diniz era vicereitor. Para Medeiros, aquele "era um movimento político nitidamente de caráter subversivo". Diniz, que estava presente àquela reunião para prestar depoimento como diretor da Faculdade de Ciências Econômicas, afirmou que Paglioli tinha dado a autorização para o evento.

Na reunião seguinte, Paglioli argumentou longamente, afirmando que tentara evitar a realização da atividade, mas que teria recebido um pedido do MEC e, por isso, não era possível impedir o uso do espaço, observando ainda que Diniz de fato o consultara sobre a questão.

Apesar da justificativa, Medeiros insistiu em atribuir a responsabilidade do episódio a Diniz, chegando a afirmar que Paglioli havia sido "iludido" e que, da parte de Diniz, não teria havido "tanta ingenuidade assim". Considerando que Medeiros e Diniz atuavam na mesma faculdade há anos, surge a possibilidade de questões pessoais também terem motivado Medeiros a manifestar-se naquele sentido.

Naquela reunião, duas outras questões foram apresentadas a Paglioli, desta feita por Buaes. Envolviam a cessão do Salão de Atos para conferência de Jacob Gorender e a não cessão do espaço para conferência de Carlos Lacerda. Em ambos os casos, Paglioli apresentou justificativas consideradas satisfatórias pelo presidente e pela maioria da CEIS (UFRGS, 1964g).

\section{Relações com a "comunidade de segurança e informações"}

Houve intensa comunicação entre a CEIS e órgãos da "comunidade de segurança e informações", notoriamente o III Exército e o DOPS/ RS. Desde a reunião de instalação, esteve presente o gen. Teixeira. O modo como essa comunicação deveria ocorrer foi motivo de debates na comissão. Alguns entendiam que cada representante deveria obter uma lista de estudantes, professores e servidores técnico-administrativos em suas respectivas unidades, que deveriam ser encaminhadas ao DOPS e ao Exército, para que fornecessem à comissão "informações que pudessem levá-la a intensificar suas atividades". Outros propunham solicitar àqueles órgãos uma lista de pessoas "comprometidas" que fossem vinculadas à UFRGS.

Diante do impasse, o gen. Teixeira determinou que "se tratasse, desde já, dos casos concretos existentes [sic], isto é, dos elementos presos e dos que, pela ausência prolongada, estão incorrendo em abandono de cargo". O militar se referia àqueles que, como Ápio Cláudio de Lima 
Antunes (professor de Direito em Pelotas), haviam se refugiado após a deposição de Goulart, diante da incerteza da conjuntura. Eles, como os que haviam sido presos, constituiriam "casos concretos", ou seja, apresentavam 'provas de subversão', na visão do militar, em função de terem sido encarcerados ou de terem se refugiado em outro país (como Antunes, que fora para o Uruguai) ou na clandestinidade.

Teixeira também definiu que as subcomissões fizessem uma primeira triagem nas listas completas obtidas em cada unidade, de modo a que somente fossem enviadas ao DOPS e ao Exército "uma relação dos elementos supostamente comprometidos", para agilizar os trabalhos daqueles órgãos (UFRGS, 1964b; 1964c).

Ao aumentar o poder decisório das subcomissões sobre o que deveria ou não ser punido, abria-se ainda mais a brecha que poderia servir para a defesa ou para a perseguição a docentes, discentes e servidores técnico-administrativos, tanto em função de congruências ou antagonismos ideológicos quanto em relação a questões de outra ordem, como divergências pessoais.

A participação do Exército, contudo, não se restringia ao fornecimento de informações. Entre 26 de maio e 4 de junho de 1964, pelo menos dezesseis professores da UFRGS foram interrogados no Quartel General do III Exército, na Rua dos Andradas, no centro de Porto Alegre (UFRGS, 1964d). Na Faculdade de Arquitetura, a convocação foi transmitida pelo diretor. ${ }^{10}$

Outra relação da CEIS com a "comunidade de segurança e informações" ocorreu por meio dos militares que atuavam como interventores nas entidades estudantis. Estes, a convite do gen. Teixeira, chegaram a participar de pelo menos uma das reuniões da comissão, ocasião na qual contribuíram fornecendo informações sobre os estudantes ligados às entidades nas quais atuavam (UFRGS, 1964b; 1964c).

\section{Considerações finais}

Um dos resultados da "Operação Limpeza” na UFRGS foi o expurgo de dezoito docentes. Dentre eles, dezesseis lecionavam em Porto Alegre e dois em Pelotas. Em 1969, mais professores daquela instituição foram atingidos, totalizando, dentre os casos conhecidos, 41 expurgos docentes na UFRGS durante a Ditadura Civil-Militar.

${ }^{10} \mathrm{Da}$ Faculdade de Arquitetura, foram interrogados Carlos Maximiliano Fayet, Demétrio Ribeiro, Edvaldo Pereira Paiva, Enilda Ribeiro, Francisco Riopardense de Macedo, Nelson Souza, dentre outros (Ribeiro; Macedo, 2006; Souza, 2007). 
Doze dos expurgados de 1964 sofreram a medida repressiva em função da CEIS. Com base no relatório apresentado ao MEC pela comissão, em 25 de setembro de 1964 foram publicados no Diário Oficial da União quinze decretos, afastando os professores. Eram decretos individuais e, no caso dos docentes que acumulavam funções, havia um para cada cargo, todos assinados por Castello Branco e Suplicy de Lacerda. Por indicação da CEIS o MEC determinou o expurgo de:

- Antônio Santos Flores (Medicina);

- Ápio Cláudio de Lima Antunes e Hugolino Andrade Uflacker (Direito de Pelotas);

- Cláudio Francisco Accurso (Ciências Econômicas);

- Demétrio Ribeiro, Enilda Ribeiro, Edgar Albuquerque Graeff e Edvaldo Pereira Paiva (Arquitetura);

- Ernani Maria Fiori (Filosofia);

- Luiz Carlos Pinheiro Machado (Agronomia e Veterinária);

- Luiz Fernando Corona (Artes e Arquitetura);

- Nelson Souza (Arquitetura e Reitoria). ${ }^{11}$

Além deles, outros foram expurgados em 1964, nos primeiros meses após o golpe, sem a sugestão da CEIS, portanto. Antônio de Pádua Ferreira da Silva foi afastado da Escola Técnica, vinculada à Faculdade de Ciências Econômicas, pelo recurso da não renovação contratual. Cibilis da Rocha Viana e Armando Temperani Pereira, da Faculdade de Ciências Econômicas, e Antônio Ajadil de Lemos e Brasil Rodrigues Barbosa, da Faculdade de Direito de Porto Alegre, foram expurgados por terem perdido seus direitos políticos após o golpe. Carlos Jorge Appel, do Colégio de Aplicação, sofreu um "expurgo indireto": teve de afastar-se do país em função de constrangimentos ligados à conjuntura política. ${ }^{12}$

Como em Universidade e Repressão foi sintetizado,

embora no seu conteúdo e nas suas motivações reais a investigação realizada na universidade tivesse caráter de pura e simples repressão político-ideológica, na sua forma ela pretendeu se revestir de um caráter jurídico que a legitimasse. $\mathrm{O}$ modo que encontrou para fazêlo foi o de imitar as formas externas de um ritual processualístico, apresentando-se a CEIS com foros de tribunal, perante o qual os professores (bem como estudantes e funcionários) eram intimados a depor, recebiam acusações e tinham prazos para apresentar suas defesas (ADUFRGS, 1979, p. 28).

\footnotetext{
${ }^{11}$ Para detalhes, ver Mansan (2009, p. 116).

12 Sobre os tipos de expurgos, ver Mansan (2009, p. 154).
} 
Essa postura da comissão correspondia ao padrão de ação do nascente regime ditatorial, marcado pela busca de legitimação para suas ações arbitrárias, particularmente através de posturas e discursos que buscavam amenizar o caráter ditatorial do regime.

Conflitos internos marcaram significativamente a atuação da CEIS. Tanto sua forma excepcional, diante das congêneres de outros estados, quanto as relações assimétricas de poder estabelecidas entre seus membros conferiram à comissão um modo de trabalho muito específico.

Diferentes interesses e comportamentos marcaram a participação de cada um daqueles professores. Muitos optaram por uma postura moderada, e alguns, como Prunes e Westphalen, buscaram desde o início sair do grupo, cada um a seu modo. Poucos questionaram, sempre de forma muito cuidadosa, algumas proposições dos membros mais poderosos. Vários preferiram o caminho mais seguro do silêncio, restringindo sua participação a breves comentários, quando solicitados.

Outros viram com bons olhos suas indicações, e pelo menos um foi voluntário para a função. Medeiros, Buaes, Messias e Monteiro tiveram intensas atuações, marcadas por significativo alinhamento ideológico com o regime ditatorial e por um comprometimento efetivo com a função repressiva da comissão.

Essa congruência ideológica, mais intensa justamente entre os membros mais poderosos do grupo, foi fundamental para o sucesso daquele projeto repressivo, pois serviu como elemento aglutinador e justificador da perseguição aos "subversivos". Um difuso anticomunismo reunia a ampla gama de perseguidos sob acusações comuns e intercambiáveis de "comunismo", "esquerdismo" e "subversão", ao mesmo tempo em que funcionava como chave para a definição de quem poderia ser considerado "confiável". É significativa a solicitação do gen. Teixeira a alguns diretores no sentido de que "indicassem cinco nomes de professores catedráticos de reconhecida fé democrática e posição anticomunista" (UFRGS, 1964e).

Tal perspectiva maniqueísta, associada a uma noção de "inimigo interno" tão difusa quão abrangente, fundamentou as investigações. Para além das motivações ideológicas, contudo, é preciso considerar a possibilidade de que alguns fossem movidos, sobretudo, pela busca de poder no campo da educação superior e, particularmente, na universidade, bem como, em outros casos, pelo medo de também serem perseguidos. 


\section{Referências}

ACCURSO, Cláudio Francisco. Sobre seu expurgo da UFRGS e sua trajetória profissional [12/01/2006]. Entrevistador: Jaime Valim Mansan. Porto Alegre.

ADUFRGS. Universidade e Repressão: Os expurgos na UFRGS. Porto Alegre: L\&PM, 1979.

ADUSP. O controle ideológico na USP (1964-1978). São Paulo: ADUSP, 2004.

DREIFUSS, René. 1964: a conquista do Estado: ação política, poder e golpe de classe. 6. ed. Petrópolis: Vozes, 2006.

INTERVENÇÃO Militar Perdura em 17 Órgãos. Zero Hora, Porto Alegre, p. 11, 29/09/1964.

MANSAN, Jaime Valim. Os expurgos na UFRGS: afastamentos sumários de professores no contexto da Ditadura Civil-Militar (1964 e 1969). 2009. 320 p. Dissertação (Programa de Pós-Graduação em História) - Pontifícia Universidade Católica do Rio Grande do Sul, Porto Alegre.

MORAES, Thiago Aguiar de. "Entreguemos a emprêsa ao povo antes que o comunista a entregue ao Estado": os discursos da fração "vanguardista" da classe empresarial gaúcha na revista "Democracia e Emprêsa" do Instituto de Pesquisas Econômicas e Sociais do Rio Grande do Sul (1962-1971). 2012 (inédita). 227 p. Dissertação (Programa de Pós-Graduação em História) - Pontifícia Universidade Católica do Rio Grande do Sul, Porto Alegre.

MORAES, Angélica de. Um tribunal de professores expurgou na UFRGS. Coojornal, Mar/1979, p. 9-10.

RIBEIRO, Demétrio. A grama entre os paralelepípedos. In: GUEDES, P. C.; SANGUINETTI, Y. (Orgs.). UFRGS: Identidade e memórias (1934-1994). Porto Alegre: UFRGS, 1994. p. 12-16.

RIBEIRO, Enilda; MACEDO, Francisco Riopardense de. Sobre a repressão na Faculdade de Arquitetura da UFRGS logo após o Golpe de 1964, sobre o expurgo de alguns arquitetos daquela escola e sobre a trajetória politica e profissional de ambos [21/09/2006]. Entrevistador: Jaime Valim Mansan. Porto Alegre.

SOUZA, Nelson. Sobre seu expurgo da UFRGS e sua trajetória profissional e politica [31/07/2007]. Entrevistador: Jaime Valim Mansan. Porto Alegre.

UFRGS. CEIS. Ata da Reunião de Instalação da Comissão Especial de Investigação Sumária. 18/05/1964a.

UFRGS. CEIS. Ata da $1^{a}$ Reunião Ordinária da Comissão Especial de Investigação Sumária. 21/05/1964b.

UFRGS. CEIS. Ata da $2^{a}$ Reunião Ordinária da Comissão Especial de Investigação Sumária. 26/05/1964c.

UFRGS. CEIS. Ata da $3^{a}$ Reunião Ordinária da Comissão Especial de Investigação Sumária. 04/06/1964d.

UFRGS. CEIS. Ata da $4^{a}$ Reunião Ordinária da Comissão Especial de Investigação Sumária. 08/06/1964e.

UFRGS. CEIS. Ata da $5^{a}$ Reunião Ordinária da Comissão Especial de Investigação Sumária. 09/06/1964f. 
UFRGS. CEIS. Ata da $7^{a}$ Reunião Ordinária da Comissão Especial de Investigação Sumária. 02/07/1964g.

UFRGS. CEIS. Subcomissão "D”. Ata da Reunião de Instalação dos Trabalhos da Subcomissão letra D, integrada pelas faculdades de Direito, Filosofia, Ciências Econômicas e Escola de Artes. 29/05/1964h.

UFRGS. CEIS. Subcomissão "D”. Ata da $1^{a}$ Reunião da Subcomissão letra D, integrada pelas faculdades de Direito, Filosofia, Ciências Econômicas e Escola de Artes. 01/06/1964i.

UFRGS. CONSUN. Ata da $312^{a}$ Sessão do Conselho Universitário. 27/09/1962.

UFRGS. CONSUN. Ata da $327^{a}$ Sessão do Conselho Universitário. 25/04/1964j.

UFRGS. CONSUN. Decisão 01/63 do Conselho Universitário. 01/03/1963.

UFRGS. Gabinete do Reitor. Circular $n^{\circ} 31$. 14/04/1964k. Fundo História do IFCH, Núcleo de Pesquisa Histórica da UFRGS, Porto Alegre.

UFRGS. Gabinete do Reitor. Circular $n^{\circ} 35$. s/d [abr-./maio 1964]. Fundo História do IFCH, Núcleo de Pesquisa Histórica da UFRGS, Porto Alegre.

Solicitado em 01/12/2011. Aprovado em 20/03/2012. 